\title{
Conservação e inovação no campo léxico do parentesco: o caso do Mbyá e do Guaraní paraguaio (Tupí-Guaraní)
}

\author{
Retention and innovation in the kinship lexical field: \\ the case of Mbyá, and Guaraní paraguaio (Tupí-Guaraní)
}

Wolf Dietrich

\begin{abstract}
Resumo
Os resultados do volume II do Atlas Lingüistico Guarani-Românico (cerca de 300 mapas), focalizado na terminologia do parentesco da zona bilingue Guaraní-Espanhol do Paraguai e de partes adjacentes do Brasil e da Argentina, com a inclusão de oito pontos de exploração indígena, Mbyá e Avá-Nhandeva, mostram a manutenção da maior parte do sistema tradicional do parentesco horizontal e vertical nas línguas indígenas (denominação dos irmãos e irmãs, dos avós, dos filhos, netos, dos primos, sobrinhos, tios e sogros). $\mathrm{O}$ elemento próprio do sistema tradicional era e é a distinção entre termos não-relacionais e termos relacionais com respeito ao sexo do falante. No Guaraní paraguaio observa-se, porém, a perda de várias distinções tradicionais, entre a referência ao homem ou à mulher, entre irmãos maiores e menores; mudanças na distinção tradicionalmente precária entre 'pai' e 'tio', 'filho' e 'primo'. A terminologia hierárquica mantém-se só no centro da família nuclear moderna.

Palavras-chave: Terminologia do parentesco. Mudança das estruturas semânticas. Guaraní antigo. Guaraní paraguaio moderno. Mbyá (Tupí-Guaraní).
\end{abstract}

\begin{abstract}
This paper presents some of the findings of the Atlas Lingüistico Guarani-Románico $(A L G R)$, which in its volume II is focused on kinship terminology in the Guarani-Spanish bilingual area of Paraguay and adjacent parts of Brazil and Argentina. The investigation includes eight indigenous exploring points (Mbyá and Avá-Nhandeva). The results (of about 300 linguistic maps) show the preservation of most of the traditional Guarani kinship terminology in Mbyá. Most peculiar in the traditional systems is the distinction between non-relational and relational forms with regard to the gender of the speaker. This paper gives the traditional kinship system as documented in Montoya $(1639,1640)$ and then the results of the $A L G R$. Modern Paraguayan Guarani shows the loss of great part of the traditional terms and their substitution by borrowings from Spanish. They include the giving up of traditional distinctions in many cases.

Keywords: Kinship terminology. Change of semantic structures. Old Guarani. Modern paraguayan Guarani. Mbyá (Tupi-Guarani).
\end{abstract}

\section{Introdução}

As línguas Tupí-Guaraní do subconjunto I (Rodrigues e Cabral 2002) são faladas do sul do Mato Grosso do Sul até o Rio Grande do Sul (Kaiowá, 
Avá-Nhandeva e Mbyá, Xetá), no sudeste da Bolívia (Guarani do Chaco ou Chiriguano, com vários dialetos, e o Tapiete), no Paraguai (Guaraní paraguaio em primeiro lugar, mas também o Kaiowá, Avá-Nhandeva e o Atxê-Guayakí) e no noroeste da Argentina (o Guaraní do Chaco e o Tapiete). De todas estas línguas Tupí-Guaraní uma não é falada por indígenas, mas por mestiços, no sentido de descendentes de colonos europeus e indígenas. É a língua Tupí-Guaraní com o maior número de falantes, uns 5 milhões no Paraguai, no noroeste argentino, em Buenos Aires e no sul do Mato Grosso do Sul. Grosso modo, trata-se do território do Paraguai colonial onde, até hoje, se manteve o Guaraní ao lado do Espanhol, e ao lado do Português em terras brasileiras. As línguas nacionais são faladas fora do seio da família, com pessoas desconhecidas, com as autoridades. O Guaraní é a língua da casa, das conversações com os amigos, com os vizinhos e com os colegas de trabalho, em lugares de trabalho tradicionais. Portanto, trata-se de uma situação diglóssica. O bilinguismo dos falantes geralmente é assimétrico: no Paraguai, o Guaraní, oficializado desde 1992, é ensinado nas escolas, e enquanto o Espanhol é a primeira língua nos núcleos urbanos, o Guaraní é dominante no campo, onde o Espanhol muitas vezes é uma língua quase desconhecida. Esta situação é muito rara na Argentina e inexistente no Brasil, onde a língua oficial é o Português.

Os dados que estão na base desta conferência sobre a terminologia do parentesco no Mbyá e no Guaraní paraguaio foram obtidos nas explorações realizadas entre 1995 e 2004, no âmbito do projeto do Atlas LingüísticoGuarani-Românico (ALGR), cujo objetivo é o de estudar e apresentar em mapas geolinguísticos o contato entre o Guaraní e duas línguas românicas, o Espanhol e o Português, faladas na zona do mencionado bilinguismo. Trata-se de um projeto internacional, levado a efeito por duas universidades alemãs, uma norteamericana e uma instituição paraguaia.

A metodologia do Atlas Lingüístico Guarani-Românico segue o modelo do Atlas Diatópico y Diastrático del Uruguay (ADDU), preparado e parcialmente publicado por Harald Thun (Kiel) e Adolfo Elizaincín (Montevidéu). Consiste em interrogar, em cada ponto de exploração, um mínimo de quatro informantes distintos, diferenciado segundo a idade e o grau de instrução (parâmetros diageracionais e diastráticos). Por razões de tempo e de economia, opomos duas classes extremas de idade, os jovens, entre 18 e 36 anos, e os idosos, com mais de 50 anos, e duas classes socioculturais: a classe sociocultural baixa definese por uma instrução até seis anos de ensino básico, a classe alta, por uma escolaridade mais avançada, do segundo grau até uma formação profissional ou universitária. Preferimos uma pluralidade simultânea de informantes, mas sempre do mesmo nível geracional ou sociocultural. O parâmetro diasexual isto é, a diferenciação entre homens e mulheres, não foi observado de maneira 
constante, mas procuramos obter grupos mistos, constituídos de, pelo menos, quatro informantes por lugar. Em muitos casos temos informantes adicionais, que servem também para compensar as imperfeições técnicas e metodológicas de algumas gravações. O questionário é constituído de umas 400 perguntas, fazendo-se a exploração com dois entrevistadores, um paraguaio ou uma paraguaia de língua materna Guaraní, que dirige a conversação, e um técnico alemão, que fiscaliza a gravação em cassete, presentemente em minidisco, e, ao mesmo tempo, faz a transcrição fonética impressionista do que escuta, agregando comentários de caráter geral, sobre a pronúncia do informante, as circunstâncias sociais etc. As explorações fizeram-se em Guaraní e a partir do Guaraní para podermos medir, em primeiro lugar, o grau de domínio desta língua. Para examinarmos o domínio do Espanhol ou do Português de cada informante, nas seções do questionário que se referem ao léxico do corpo humano e aos termos de parentesco, se pedem os termos espanhóis ou portugueses correspondentes aos do Guaraní, ao passo que a inteira seção gramatical se referencia na sintaxe do Espanhol/Português.

O objetivo do $A L G R$ é registrar a variação linguística do Guaraní e do Português, respectivamente do Espanhol, e o grau da influência mútua. A variação pode ser de caráter diatópico, diastrático, diageneracional, diasexual e diafásico e refletir, além disso, o grau de competência de cada falante em cada uma das línguas. Geralmente uma delas, ou o Guaraní ou a primeira língua nacional, o Espanhol, respectivamente o Português, é dominante e impõe-se à outra. Foram explorados 77 pontos no total, 37 no Paraguai, 32 na Argentina e 8 no Brasil; da totalidade de 77 pontos, 8 são pontos de exploração indígenas, quase todos de Mbyá.

As perguntas, na parte introdutória, referem-se a dados sociolinguísticos ${ }^{1}$. Seguem uma parte fonológica, que se refere ao Guaraní local, e duas partes centrais dedicadas ao léxico, em particular ao léxico do corpo humano e defeitos corporais, e ao parentesco.

A terminologia do parentesco é a que nos interessa aqui. Ela é interessante com respeito ao Guaraní, já que o sistema tradicional, que refletia os costumes matrimoniais e as relações sexuais comuns entre os Guaraní tribais, era muito diferente do dos espanhóis e portugueses.

\footnotetext{
${ }^{1}$ Os resultados da parte sociolinguística, somente das enquetes realizadas no Paraguai foram publicadas em Thun, Harald (2002), Atlas Lingüístico Guarani-Románico - Sociología, I-II, Kiel: Westensee-Verlag. A coleção de dados regular foi ampliada por um grande número de enquetes adicionais. $\mathrm{O}$ volume I contém o atlas, o volume II comentários originais dos informantes, em geral em Guarani, com a tradução castelhana ao lado.
} 


\section{0 sistema tradicional da terminologia do parentesco Guaraní}

A documentação mais antiga do sistema tradicional do parentesco Guaraní é a do padre Antônio Ruiz de Montoya no final de seu Vocabulário da língua Guaraní, de 1640. Ele reflete a situação da família Guaraní do início do século XVII que os missionários queriam mudar para acabar com a poligamia dos indígenas e introduzir o matrimônio cristão.

O estudo da terminologia do parentesco Guaraní em grande parte depende dos conhecimentos que temos das práticas sociais dos Guaraní. Isto significa que depende do conhecimento etnográfico sobre os laços familiares dentro da sociedade Guaraní. O único estudo que pude encontrar é um trabalho etnolinguístico sobre "Parentesco e organização social Kaiowá", de Levi Marques Pereira, de 1999. O que ele escreve sobre os Kaiowá pode servir como modelo para os Mbyá, sem que tenhamos conhecimentos exatos sobre estes últimos.

\subsection{A base biológica}

A base biológica do grupo ou da família é kuña 'mulher' e kuimba'e 'homem, varão', sendo ava o termo para 'pessoa, homem', especificamente para o caso normal da existência de pessoas em épocas pré-colombianas, isto é para o índio. O homem branco, o espanhol, chamava-se de karai, termo que, segundo Montoya (1639:90 v.), significava 'astuto, hábil' e se usava para designar os feiticeiros. Depois do contato com os espanhóis, se usava também para designar aqueles e, muito impropriamente, segundo Montoya, "o nome cristão e as coisas benditas" (tradução minha).

\subsection{O núcleo familiar}

A união de mulher e homem constituía a relação horizontal de $m e(n)$ 'marido, esposo', che mẽ 'meu esposo' e t-embireko 'esposa', che r-embireko 'minha esposa', literalmente 'a por mim possuída', che r-embi-reko, particípio passivo do verbo a-reko 'ter, possuir'. Do ponto de vista da mulher, o casamento era menda, termo que obviamente tem que ver com me(n) 'marido'. O homem simplesmente dizia che r-embireko-rã ai-pysy 'peguei na minha futura esposa' (Montoya 1640:140). O casamento, segundo nossos conhecimentos, não se fazia com cerimônias específicas, nem implicava as promessas mútuas do casamento cristão que queriam introduzir os missionários jesuítas. Também por isto não existia um termo nem para 'casal', nem para 'família'. Este conceito de tradição europeia tinha seu papel também nas explorações do $A L G R$, sem verdadeiro resultado (vejam-se as seções 2.1. e 3.2.). Montoya (1640:278) oferece termos analíticos como og-peguára 'os que pertencem à casa', ta'y-reta 'conjunto dos 
filhos' ou che r-e'ýi 'minha genealogia', che ñemoñangá-va 'minha geração, meu clã', etc.

\subsection{Relações ascendentes}

'Pai' e 'mãe', túßa e sy, formavam o núcleo da família em sentido ascendente. O pai do pai ou da mãe, o 'avô' era tamõi, a mãe da mãe ou do pai, a 'avó', se dizia jarýj. A diferença com o sistema que queriam introduzir os missionários jesuítas estava na linha descendente, na dos filhos e das filhas. Tem que ver com os costumes matrimoniais, com as estruturas patrilocais e patrilineares dos Guaraní. A esposa que, por matrimônio, entrava na casa do esposo era, deste momento em diante, a esposa não só de seu marido, mas também de seus irmãos maiores. Em outras palavras, os irmãos maiores tinham direitos sexuais que os menores não tinham. Daí a importância da distinção entre irmãos maiores e menores para os irmãos mesmos, ao passo que a distinção entre as irmãs maiores e menores não a faziam os varões, mas só as irmãs entre elas. Veremos tudo isto no que segue. Mas uma das consequências importantes destes direitos e deveres dos homens era que a distinção entre os conceitos 'pai' e 'tio paterno' não tinha muito sentido. Podia-se distinguir o tuvy 'tio paterno' do túßa 'pai', mas esta distinção não era nem obrigatória nem frequente. Montoya não diz nada sobre isso porque ele estava interessado em manter a distinção, queria que caíssem no esquecimento os costumes tradicionais dos Guaraní, mas várias outras línguas Tupí-Guaraní, o Chiriguano, o Guaraio e o Kamaiurá ignoram o termo tuvy, isto é que não designam o tio paterno por um lexema específico. Filhos e filhas recorrem ao pai ou um dos seus irmãos maiores pela expressão che ru! 'meu pai/meu tio (paterno)'. Por outro lado, é evidente que o 'tio materno', tuty, era e é uma realidade também terminológica, isto é, lexical. Ele se designava por um lexema específico, tuty.

Para o conceito 'padrasto' Montoya (1640:399) menciona tuvanga, isto é tuv-anga 'pai postiço, substituto do pai' ou também 'padrinho'. Montoya menciona também a circunlocução che sy mẽ 'o esposo de minha mãe', termos que se mantêm sobretudo no Guaraní paraguaio (veja-se a seção 3.2.) Consequentemente, a 'madrasta' era sy anga 'mãe postiça, substituto de mãe', mas também se dizia tuvaty ou tuv-aty, literalmente a 'amontoação do pai', 'a que está juntada ao pai'. Este último termo não se encontra nas formas modernas do Mbyá e do Guaraní paraguaio.

A 'tia materna, irmã maior da mãe' era sy'y, a 'tia materna, irmã menor da mãe' designava-se por sy' $y k y$, de $s y$ ' $y$ 'tia materna' e $k y(p y$ ' $y)$ 'irmã menor (com referência à irmã maior)'. A 'tia paterna' era jaiche, sem distinção hierárquica, já que para os varões a ordem dos nascimentos das irmãs do pai não tinha 
importância porque dela não resultavam mais ou menos direitos para eles. É aqui que já se vê que, no sistema tradicional do parentesco Guaraní, existiam termos não relacionais, sem referência ao sexo natural do falante, como sy 'mãe (de homem ou de mulher)' e tú $\beta a$ 'pai (de homem ou de mulher)', e termos relacionais com referência ao homem ou à mulher, como sy'y 'tia materna, irmã maior' e sy'yky 'tia materna, irmã menor', neste caso com referência à mulher, em especial à ordem dos nascimentos de suas irmãs. Por outro lado, jaiche 'tia paterna' era um termo relacional com referência ao pai e aos varões em geral, já que para o pai as qualidades de 'irmã maior' ou 'irmã menor' eram sem importância no âmbito das relações estabelecidas com elas.

Não queremos falar aqui em termos como "fala do homem" ou "fala da mulher”, já que, na realidade, a distinção não depende do sexo natural do falante, mas da referência que o falante ou a falante faz às distinções usuais dos varões e das mulheres. Porém, para simplificarmos a terminologia, vamos falar em "termos do homem" e "termos da mulher". No caso dos termos não relacionais, a distinção que se faz é, geralmente, a que existe entre os sexos naturais.

\subsection{Relações descendentes}

$\mathrm{Na}$ linha descendente de pais a filhos observamos termos relacionais, já que se distinguem filhos e filhas com referência ao pai, ao passo que a mãe não distinguia entre o sexo masculino ou feminino de seus filhos, mas falava só de cria ou de crianças. O pai tinha que falar em seus filhos, che r- $a$ ' $y$, e suas filhas, che r-ajy, mas a mãe dizia só che memby 'minha cria/ criança'.

O homem chamava os enteados de ta'y ranga 'filho postiço, substituto de filho' e tajy ranga 'filha postiça', a mulher de memby ranga 'criatura postiça'.

A supremacia e liberdade sexual do varão guaraní refletiam-se também na não distinção lexical entre 'filhos' e 'primos'. Não se documentaram termos específicos para 'primo', 'prima', mas só existiam termos descritivos como che ruvy ra'y 'o filho de meu tio paterno', che tuty ra'y 'o filho de meu tio materno' ou che ruvy rajy 'a filha de meu tio paterno', etc. Estes são termos delocutivos empregados por outros membros da família ou por pessoas alheias à família. Os tios e os pais chamavam os filhos ou primos de che ra 'y 'meu filho' e as filhas ou primas de che rajy 'minha filha'. As tias também usavam termos descritivos para falar de seus primos a terceiros, mas empregavam o termo alocutivo che memby 'minha criança' para dirigir-se a eles ou a elas, isto é, sem distinguir entre seus próprios filhos e os primos, filhos ou filhas de seus irmãos ou suas irmãs.

$\mathrm{Na}$ terminologia do Guaraní clássico distinguiam-se quatro tipos de sobrinhos, segundo a genealogia e o sexo natural do irmão ou da irmã de 
que descendia o sobrinho ou a sobrinha. Não se distinguia o sexo natural do sobrinho/da sobrinha como se faz em Português. Mais uma vez se trata de termos relacionais com referência dupla ao homem e à mulher, segundo a relação dupla em sentido horizontal e no sentido da geração descendente: jetipe 'sobrinho, -a, filho, -a de um dos irmãos do varão'; $i$ 'y 'sobrinho, -a, filho, -a de uma das irmãs do varão', che r-i'yr 'meu sobrinho/minha sobrinha', ñomemby 'sobrinho, -a, filho, -a de uma das irmãs da mulher' e peng 'sobrinho, -a, filho, -a de um dos irmãos da mulher'.

Com respeito aos netos, a sociedade Guaraní tradicional também distinguia entre o sexo natural do antepassado, não do neto ou da neta: Temirarirõ eram os netos da mulher, da avó, temimino os netos do homem, do avô. Existe terminologia relacional aqui também.

\subsection{Relações horizontais}

Uma das diferenças entre o Português moderno e o Guaraní tradicional é que as relações entre os membros da mesma geração consanguínea dos filhos e filhas designava-se, no Guaraní tradicional, por termos relacionais com referência ao irmão ou à irmã e que as relações são verticais com referência ao mesmo sexo, tanto dos irmãos como das irmãs, sempre com referência àquele/ àquela que era maior ou menor. $\mathrm{O}$ irmão tinha interesse em distinguir entre seus irmãos maiores, $t$-yke' $y /$ che $r$-yke' $y$, e menores, tyvy/ che $r$-yvy, porque os maiores tinham mais direitos e deveres que os menores. Isto não era o caso na relação para com as irmãs do homem, daí serem designadas por um termo único, t-eindy/ che r-eindy 'minhas irmãs'. De maneira inversa, as irmãs tinham interesse em distinguir entre as maiores, $t-y k e /$ che $r-y k e$, e as menores, che kypy'y, já que as maiores tinham mais direitos e deveres nos trabalhos da casa que as menores. Em grande simetria com os irmãos, os deveres das irmãs para com os irmãos dependia só do sexo natural deles, razão pela qual só tinham um único termo relacional, che kyvy 'meu irmão', que se percebia numa relação horizontal.

\subsection{Parentesco por aliança}

No Guaraní antigo tal como é documentado por Montoya (1639:1640), o varão não dispunha de um termo próprio para 'genro', ele dizia che rajy mẽ 'o marido da minha filha'. A sogra dizia che peũ 'meu genro', termo que não se conservou no Guaraní moderno, também não no Mbyá. O sogro podia chamar a nora de che rajy raty, enquanto a sogra dizia che memby taty 'minha nora'.

Ao contrário, o genro chamava o sogro de che r-atyu 'meu sogro', a nora chamava-o de che mendúva, palavra composta de mẽ + -úva 'pai do meu 
marido, sogro'. A sogra chamava-se de t-aicho, che r-aicho 'minha sogra' na boca do genro ou desde o ponto de vista de outro varão, enquanto a nora dizia che mend-y 'engendradora de meu marido, minha sogra'.

Os cunhados e as cunhadas formam um tipo de parentesco por aliança que reflete, pelo menos parcialmente, as hierarquias e distinções lexicais que existiam no Guaraní antigo: T-ovaja/ che r-ovaja 'aquele que está em frente de mim' era o 'cunhado do esposo', do homem: expressão de uma relação horizontal. A 'cunhada do homem', na sociedade Guaraní tradicional, de propósito, se confundia com a nora, esposa do filho, t-aty, che r-aty, expressão de uma relação vertical. Deste modo, o irmão dizia che ryke'y taty 'a nora de meu irmão maior', cunhada sobre a qual não tinha direitos, ou che ryvy raty 'a nora de meu irmão menor', mulher sobre a qual tinha os mesmos direitos como com respeito à sua verdadeira nora. Neste caso, o conceito de 'cunhada', na nossa compreensão moderna, não existia. Para a mulher havia uma terminologia relacional diferente: ela designava seus cunhados, irmãos de seu esposo, por termos descritivos como che mendyvy 'o irmão menor de meu esposo' ou che meryke' $y$ 'o irmão maior de meu esposo', che kypy'y me 'o esposo de minha irmã menor' ou che ryke me 'o esposo de minha irmã maior'. Todas estas expressões testemunham uma relação vertical. A cunhada, esposa de meu irmão, era $u k e$ 'i, che uke'i 'minha cunhada', expressão de relação horizontal para com o outro sexo do irmão.

\section{Conservação no Mbyá}

Da terminologia do parentesco Guaraní tradicional apresentada aqui conservou-se muito em sociedades tradicionais Guaraní como são ainda as dos Mbyá. A língua dos Mbyá está documentada em Dooley (2006) e nas explorações realizadas para o projeto do $A L G R$. Baseamo-nos, principalmente, nestas explorações, consultando Dooley (2006) para a grafia do Mbyá $(<\mathrm{x}>$ representando /ts/ antes de /a/, /e/, /i//,ty/ antes de /o/, /u/,/it/), para informações complementares e para os casos de dúvida.

\subsection{Base biológica e núcleo familiar}

Na base biológica, kuña 'mulher' é o termo básico também em Mbyá; porém, *kuimba'e 'homem, varão' não se conhece nem em Mbyá nem em AváNhandeva. Eles dizem ava 'homem, varão', palavra documentada também por Montoya (1640), mas que se referia ao indivíduo em geral, ao conceito de 'pessoa', sobretudo ao indígena. No Guaraní paraguaio atual, ava é o 'ser humano', especialmente o indígena, mas não significa 'homem, varão'.

Com respeitos aos esposos, mẽ é o 'marido', como no Guaraní antigo, mas a 'esposa' chama-se de xe r-embireko 'minha esposa', como no Guaraní antigo, 
com a diferença de que, em algumas regiões, -embireko é a esposa antes de ter filhos e xe r-a'yxy 'a mãe de meus filhos' depois de ter filhos. Em outras regiões, xe ra'yxy pode significar 'esposa' antes e depois de ter filhos, ainda para outros falantes xe rembirekó é o termo genérico sem distinção.

Os equivalentes aproximativos Mbyá para o conceito 'família' são xe $r$-etarã 'meus parentes' ou xe r-o-pe-ygua 'os que pertencem à minha casa'.

\subsection{Relações ascendentes}

Conservou-se, sobretudo, a distinção entre termos relacionais e termos não relacionais. Salvo algumas variantes fonológicas e morfológicas como, por exemplo, -u, xe r-u 'meu pai', em lugar de tú $\beta a$, ou $x y$ 'mãe' em lugar de sy, todos os termos das gerações ascendentes e as descendentes se conservaram em Mbyá. Na designação dos padrastos observamos a peculiaridade do uso de t-uvy, xe r-uvy 'meu padrasto' (veja-se também mais embaixo). A madrasta, ao contrário, chama-se de xe xy ranga 'minha mãe substituta', 'minha padrasta', conforme a expressão che sy anga do Guaraní antigo.

Para as gerações ascendentes laterais conservaram-se jaixe 'tia paterna, irmã do pai' e $x y$ ' $y$ 'tia materna, irmã maior da mãe', também tuty 'tio materno'. O maior problema que continua existindo é aquele dos costumes matrimoniais atuais dos Mbyá, sobre os quais nos podemos informar só em Pereira (1999). Com respeito às designações dos tios é interessante ver que em Mbyá o termo tuvy significa 'padrasto' e que o 'tio paterno, com referência a um varão', se diz tuvy' $i$ ou, melhor na forma alocutiva, xe r-uvy' $i$ 'tiinho!'. Este uso da palavra revela a realidade social, isto é, que não há distinção entre 'padrasto' e 'tio', mas, por outro lado, parece que se distingue o pai do padrasto. Aliás, o termo existe em várias línguas TG com o significado geral de 'pai de criação', seja o tio materno ou o padrasto: Asuriní do Tocantins e Tapirapé xe rowyt, Kayabí je ruwyt, Kagwahiva ji-ruvyr 'primeira geração ascendente de homem e mulher'.

\subsection{Relações descendentes}

Com respeito aos sobrinhos, conservaram-se em Mbyá até hoje os termos sintéticos do Guaraní antigo e de outras línguas TG. Jasipe/ jaxipe são os sobrinhos/as sobrinhas, filhos e filhas de um dos irmãos do varão; xe ri'y ou xe ry'y são os filhos e as filhas de uma das irmãs do varão. Com referência à mulher, a situação diverge do Guaraní antigo: xe pẽ não é 'filho ou filha de um dos irmãos da mulher', mas 'da irmã da mulher'. O ñomemby 'sobrinho, -a de uma das irmãs da mulher' de Montoya (1640) não se conhece. O termo genérico da mulher é xe memby kyrĩ 'minha criança pequena, criancinha, sobrinho ou sobrinha'. 
$\mathrm{Na}$ designação dos filhos e filhas por parte do varão e da mulher quase não há diferença com o Guaraní antigo: $\mathrm{O}$ homem distingue entre $x e$ ra' ' $\mathrm{meu}$ filho' e xe rajy 'minha filha' e a mulher tem outras expressões. A única diferença entre as estruturas semânticas do Guaraní antigo e as do Mbyá está na extensão semântica de memby. A mulher mbyá distingue entre o sexo das suas crianças, xe memby 'minha filha' e xe pi'a 'meu filho' enquanto, no Guaraní paraguaio, no Kaiwá e no Guaraní do Chaco e no Guarayo, che memby significa 'minha criança sem distinção de sexo'. Por outro lado, piá 'menino' entrou também no Português brasileiro; além disso, é recorrente em várias línguas TG, em algumas parece que significa 'pequeno' ou 'pedaço'. O estudo comparativo parece confirmar a hipótese de que $p i$ 'a tem que ver com a palavra para 'testículos', tapi'a.

Os enteados, em Mbyá, chamam-se de xe ra'y ranga 'meu enteado' e xe rajy ranga 'minha enteada' para o varão, enquanto a mulher diz xe pi'a ranga 'meu enteado' e xe memby ranga 'minha enteada'. A diferença com o Guaraní antigo está na forma $r$-anga, variante de anga. As duas formas têm que ver com a raiz lexical - a'anga ou até - a'angaa 'imagem (de alguma coisa)', como se o parentesco por casamento e não consanguíneo fosse só um parentesco 'imaginado', não verdadeiro.

Conservaram-se em Mbyá os termos relacionais tradicionais para designar os netos. Conservou-se bem o termo temiarirõ, xe r-emirarirõ 'neto, -a da avó'. Para dizer 'neto, -a do avô' se observa certa inseguridade linguística na fala de alguns mbyá jovens, que usam formas como xe r-amiguinõ, r-amaminõ, r-ameminõ em lugar do tradicional xe r-amyminõ.

\subsection{Relações horizontais}

No que diz respeito aos irmãos, conservaram-se todos os termos que refletem as relações verticais com referência ao mesmo sexo e os que exprimem a relação horizontal com referência ao outro sexo, relação sexualmente tabu entre irmãos. No caso de xe r-yke'y 'irmão maior do homem', se distingue uma forma alocutiva, breve, xe ke' $y$, da forma delocutiva, plena, xe r-yke' $y$. As outras formas mencionam-se na seção seguinte, na qual se fala dos primos e das primas.

Em Mbyá, primos e primas não se distinguem dos irmãos e irmãs. O que conta é a relação vertical, ascendente ou descendente. Deste modo, os primos distinguem entre seus primos mais velhos, xe ryke' $y$, e mais jovens, $x e$ ryvy; as primas entre as maiores, xe ryke, e as menores, xe kypy'y. Não temos documentados os termos que os primos usam para suas primas e as primas para os primos do outro sexo. Também não se mencionam no dicionário de Dooley (2006). 


\subsection{Parentesco por aliança}

Como no Guaraní antigo, os Mbyá de hoje dizem xe rajy mẽ 'o esposo da minha filha', 'genro' com respeito a uma pessoa masculina que fala, enquanto a mulher diz xe memby mẽ 'o esposo da minha filha'. A 'nora', com respeito a um falante masculino, é xe ra' $y$ ra' $y x y$ 'minha nora', enquanto uma mulher diz xe pi'a ra'yxy 'a esposa de meu filho, minha nora', i-pi'a ra'yxy 'sua nora' na fala de uma mulher.

Como no Guaraní antigo, o varão mbyá distingue entre xe r-atyu 'meu sogro' e xe r-aixo 'minha sogra', enquanto a mulher mbyá faz a diferença entre хе mẽ ru 'padre de meu marido', 'meu sogro' e xe mẽ xy 'mãe de meu marido', 'minha sogra'.

No caso da terminologia dos cunhados e cunhadas se constata câmbio linguístico em vários sentidos. O lexema t-ovaja, xe r-ovaja não se usa só para 'cunhado', mas também para 'cunhada'. Thun (2005:76-77, 88-89) acha que se trata de um hispanismo ou lusismo, segundo o modelo de cunhado, cunhada, que distingue, sim, o sexo natural do cunhado, mas não exprime a referência ao varão de quem o cunhado é cunhado. Thun vê esta mudança no contexto do declínio do uso e conhecimento do termo $u k e$ ' $i$, um pouco mais conhecido na variante alocutiva $k e$ 'i. Acho que todas estas não podem ser as únicas razões das diferenças, uma vez que o elemento -ovajar significava 'cunhado' e 'cunhada' já no Guarayo dos anos 1920, documentado por Alfredo Hoeller (1932), língua certamente não muito influenciada pelo Espanhol boliviano daquela época. Os termos relacionais mencionados acima (cf. 1.6.) para o Guaraní antigo, che ryke'y taty, che ryvy raty, che mendyvy etc., não se encontram no Mbyá moderno. Não temos mais traços linguísticos da supremacia do homem perante suas cunhadas, nem traços dos termos relacionais usados pela mulher na época do Guaraní antigo.

\section{Conservações e inovações no Guarani paraguaio}

O Guaraní paraguaio moderno é um Guaraní que, desde há séculos, está em contato intenso com o Espanhol. Tanto o Guaraní influencia a fonologia, a morfossintaxe e o léxico do Espanhol regional do Paraguai como o Espanhol influencia, de forma análoga, o Guaraní. Na província argentina de Corrientes se fala outro dialeto Guaraní, o Guaraní correntino, cuja hispanização está ainda mais avançada (Cerno 2012). Os falantes do Guaraní não querem "falar como os indígenas", como eles dizem, portanto, falam com as duas línguas, Guaraní e Espanhol, no mesmo discurso (veja-se Dietrich 2010). Parcialmente há mistura das duas línguas nas estruturas morfossintáticas e no léxico, como vamos ver, mas o comportamento que têm na fala consiste na sucessão de frases 
em Guaraní e em Espanhol, muitas vezes pela repetição do que se tem dito, como para se assegurar da compreensibilidade da sua fala. É preciso saber que alguns falantes não são fluentes em Espanhol, outros não entendem tudo o que se diz em Guaraní.

\subsection{O que é o Guaraní paraguaio moderno}

Dessa situação resulta que a terminologia do parentesco sofreu mudanças consideráveis. A maior razão das mudanças linguísticas é a mudança das estruturas sociais. Abandonou-se a família extensa, o clã, perdeu-se também a supremacia absoluta dos pais e dos irmãos mais velhos. Na verdade, não sabemos muito sobre a realidade social no Paraguai (vejam-se Service 1954 e Domínguez 1966) e na zona bilíngue argentina e na brasileira, mas supomos que já não é a de antes. Os resultados de nossas explorações para o Atlas Lingüístico Guarani-Românico mostram a boa conservação das estruturas tradicionais no Mbyá, sobretudo da distinção entre termos relacionais e termos não relacionais. Entretanto, no Guaraní paraguaio e correntino atual as estruturas léxicas são bem diferentes. Nessa altura é importante esclarecer o fato de que não há descendência direta entre o Guaraní antigo e o Mbyá, mas que o Mbyá tem sua história própria, história que ignoramos quase completamente. Mas também o Guaraní paraguaio moderno, segundo os estudos recentes de vários especialistas, não se pode relacionar diretamente com o Guaraní da época jesuítica documentado por Montoya. As mudanças morfossintáticas e lexicais são grandes demais para caber no período de somente dois séculos e meio que nos separam do fim das Reduções jesuíticas, onde se praticava o que hoje chamamos o Guaraní clássico ou antigo. A documentação do Guaraní moderno já começa 50 anos depois da abolição da ordem dos jesuítas no Paraguai.

\subsection{Conservação na terminologia do parentesco}

No Guaraní paraguaio moderno, o que se mantém com firmeza é a terminologia básica, a da base biológica como kuimba'e 'homem' e kuña 'mulher' e a do núcleo familiar como che ména 'meu marido' e che r-embireko 'minha esposa'. Uma das caraterísticas do léxico do Guaraní paraguaio é a da conservação das formas longas, com o sufixo átono - $a$ do antigo caso argumentativo do Tupinambá, caso que nunca funcionou nas línguas do subconjunto I, proposto por Rodrigues e Cabral (2002). Ainda não se sabe muito sobre a origem destas formas no Guaraní paraguaio moderno.

Conservaram-se também os termos da primeira geração ascendente, túva 'pai', che r-u 'meu pai' e sy 'mãe', che sy 'minha mãe'. Igualmente, para 'padrasto', observamos o uso de túa anga, che r-u anga 'meu pai substituto', 
'meu padrasto', mas também che r-u r-ekovia 'o substituto de meu pai', 'meu padrasto'. A mulher pode dizer também che sý ména 'o marido da minha mãe', circunlocução preferida dos informantes jovens, mulheres e homens. Da mesma maneira, a madrasta chama-se de sy anga ou che sy r-ekovia 'substituto de minha mãe', 'minha madrasta'. Chama a atenção que a forma anga aparece em duas variantes, anga e 'anga (che ru'anga, che sy'anga), isto é, sem e com corte glotal em posição intervocálica. Por outro lado, hispanismos como che padrástro 'meu padrasto' ou che madrástra 'minha madrasta' são sempre possíveis e aceitáveis, pelo menos na língua falada.

Conservaram-se, em geral, os termos que se referem à geração descendente, embora sejam relacionais: $t$ - $a$ 'ýra, che r-a'y 'meu 'filho', t-ajýra, che r-ajy 'minha filha', com referência ao varão, e memby, che memby 'minha criança', com referência à mulher. Só alguns informantes jovens, sobretudo da classe alta, em regiões periféricas argentinas da zona bilíngue, mostravam certa insegurança com respeito ao valor relacional, pensando que, por exemplo, che $r a^{\prime} y$ era termo também com referência à mulher ou que memby era um termo genérico para 'filhos', também com referência aos homens.

O uso das mencionadas formas para 'filho', 'filha' particamente implica a conservação e o uso das expressões para os enteados: che ra'y'anga 'meu enteado (por parte do varão)' e che rajy'anga 'minha enteada (por parte do varão)' são as formas comuns. A mulher diz che memby'anga.'meu enteado/ minha enteada'. Em todos os casos, as formas com o corte glotal intervocálico são as mais frequentes. A alternativa pela circunlocução, che ména ra'y 'o filho de meu marido', 'meu enteado', também se usa.

Quanto ao conceito 'família', o levantamento de dados realizado para o $A L R G$ II mostra a continuação da inexistência lexical desta noção no Guaraní paraguaio. Existem as formas equivalentes àquelas que foram mencionadas anteriormente (1.2.), mas nenhuma delas corresponde exata e plenamente ao significado de 'família' no sentido que a palavra tem em Português e em outras línguas de tradição europeia. O termo te'ýi ou te'ỹi (mapa 5) mais se conhece com a acepção de 'indígena' do que com aquela de 'família' ou 'irmão'. Os termos descritivos che r-oga-pe-guára ou a variante menos comum che r-o-pegua 'os de dentro da minha casa', 'os familiares', também não correspondem à noção requerida, razão pela qual a maioria dos informantes os aceitam como possíveis, mas não os usam realmente no sentido de 'família'. Uma possibilidade geralmente aceita é o uso do hispanismo che família 'mi família'. Esta é uma solução pragmática e, ao mesmo tempo, indício do enriquecimento do vocabulário do Guaraní, lá onde faltam as expressões tradicionais. 


\subsection{Redução das distinções relacionais e hispanização da terminologia}

Observa-se abandono de todas as outras estruturas relacionais, tanto ascendentes como descendentes. Com respeito aos 'tios, não se conservou a terminologia tradicional, mas se adotou a terminologia espanhola e portuguesa, tio e tia, que é igual com referência aos irmãos e irmãs do pai ou da mãe e só permite distinguir o sexo natural do tio ou da tia, que não era o critério principal na terminologia indígena.

Na designação da segunda geração ascendente, do avô e da avó, se observa um esquecimento quase completo. Che r-amói 'meu avô' e che jarýi 'minha avó' não se usam. Che ramói é um termo que não se conhece nem mesmo de maneira passiva, ao passo que jarýi é palavra geralmente conhecida passivamente no Paraguai e no Mato Grosso do Sul, mas não no Guaraní correntino (veja-se o mapa 1). As palavras que se usam como se fossem lexemas do Guaraní são os hispanismos populares aguélo, taitá 'avô' e aguéla 'avó'.

\subsection{1 'Irmãos' e 'irmãs'}

Perdeu-se também o uso da terminologia relacional para 'irmãos' e 'irmãs' . Alguns termos mantêm-se na memória, nos conhecimentos passivos, muitas vezes, porém, com traços que refletem confusão entre as referências masculinas ou femininas e entre as hierarquias etárias, sobretudo na classe alta. Geralmente, é a geração mais velha da classe baixa que melhor conserva os conhecimentos linguísticos. De todos os termos aquele que melhor se conservou é o termo que só inclui a referência horizontal à irmã, mas não a referência vertical com respeito à hierarquia etária: che reindy 'minha irmã com referência ao varão' é o termo mais conhecido e também usado, até nas partes argentinas e brasileiras da nossa zona de exploração. Ao contrário, che r-yke 'minha irmã maior (do ponto de vista da mulher)' é um dos termos ainda lembrados da geração mais velha do Paraguai e do sul do Mato Grosso do Sul, mais praticamente desconhecido na Argentina (veja-se o mapa 2).

Che ryke'y 'meu irmão com referência ao varão' é o termo melhor lembrado, sobretudo na geração mais velha. Só no Guaraní correntino se observa a perda completa de todos os termos, mantendo-se só o hispanismo che ermáno, che ermána, também no Brasil, onde falar Guaraní sempre inclui falar Espanhol como segunda língua. O Português, neste caso, é uma terceira língua que quase não entra em contato com o Guaraní. 


\subsection{2 'Primos', 'sobrinhos' e 'netos'}

Com respeito aos conceitos 'primo', 'prima', aparentemente se perdeu todo traço da antiga terminologia relacional mencionada anteriormente, já que se adotou nada mais que o hispanismo che prímo 'meu primo' e che príma 'minha prima'. Surpreende, porém, o resultado de nossas explorações segundo o qual parece que nenhum dos termos sugeridos, nem os descritivos em Guaraní nem os hispanismos são populares. Alguns comentários de informantes corroboram a hipótese da sobrevivência de certos costumes antigos. Parece que o conceito de 'primo', 'prima' não tem um papel muito importante nas famílias extensas que continuam existindo no Paraguai e no nordeste argentino. Faltam aqui estudos sociológicos sérios sobre a realidade atual.

A terminologia relacional que, no Guaraní antigo, se referia e que, no Mbyá, ainda se refere aos 'sobrinhos' também se perdeu completamente no Guarani paraguaio e correntino. Os termos descritivos como, por exemplo, che ryke membykuimba'e 'o filho de minha irmã mais velha, meu sobrinho (com referência ao sistema de uma mulher)' não são populares, ademais de não serem verdadeiros lexemas, mas sintagmas, não dignos de entrar num dicionário. Os termos que se usam são os hispanismos che sovríno 'meu sobrinho' e che sovrina 'minha sobrinha'. Perdeu-se a estrutura relacional do Guaraní tradicional e o material léxico específico da tradição.

Igual resultado para o conceito 'neto', 'neta'. Já não se faz distinção com respeito à origem, o avô ou a avó, mas só ao sexo do neto ou da neta, critério não importante para o Guaraní tradicional. $\mathrm{O}$ termo usado com referência ao avô, temimino, perdeu-se completamente e o termo usado com referência à avó, temiarirõ, é uma lembrança de muito poucos informantes, sobretudo informantes do Paraguai. Os poucos não indígenas que se lembram do termo são informantes idosos da classe baixa; os jovens da classe alta que conhecem a palavra a aprenderam na escola. A escola assim contribui para a aprendizagem de um estilo literário, com menos hispanismos e com certos arcaísmos que estão à disposição, mas não se usam na fala cotidiana.

\subsubsection{Parentesco por aliança}

Na designação do genro, praticamente não há mudança, já que no Guaraní antigo, o sogro ou outro varão só dispunha da expressão analítica che rajy mẽ, hoje che rajy ména 'o esposo da minha filha'. A sogra ou outra mulher, depois do abandono de che peũ (1.6.), usa a expressão analítica che memby ména 'o esposo da minha criatura'. Também na designação da nora se observa a perda dos termos específicos do Guaraní antigo (veja-se 1.6.), substituídos pelas expressões analíticas che ra'y r-embireko 'a esposa de meu filho' e che memby $r$-embireko 'a esposa da minha criatura'. Na realidade, estas são expressões 
delocutivas, usadas quando se fala sobre o genro ou a nora. No tratamento alocutivo, geralmente se usa o nome da pessoa. Em todos os casos é possível o uso dos hispanismos che jérno 'meu genro' e che nuéra 'minha nora', termos que ainda mais nivelam as distinções tradicionais do que os termos analíticos do Guaraní.

Perderam-se também os termos tradicionais da designação dos sogros, che r-atyu, mendúva, cher-aicho e mendy.(c.f. 1.6.). Só existe a opção do hispanismo, geralmente preferido à expressão analítica, delocutiva. Assim, os termos mais usados são che suégro, às vezes che sógru no Brasil, respectivamente che suégra ou che sógra. Os termos analíticos encontrados são che r-embireko $r$ - $u$ 'o pai da minha esposa', 'meu sogro' e che r-embireko sy 'a mãe da minha esposa', 'minha sogra' por parte do varão, enquanto a mulher diz che ména $r$ - $u$ 'o pai do meu marido', 'meu sogro' e che ména sy 'a mãe do meu marido', 'minha sogra'. $\mathrm{O}$ arcaísmo che r-aicho 'minha sogra (por parte do varão)' foi aceito só em pouquíssimos casos por informantes não indígenas, como arcaísmo já não usado (veja-se o mapa 3). As formas breves meru, de mẽ ru 'pai do esposo', 'sogro' e mesy, de mẽ sy 'mãe do esposo', 'sogra', ambas por parte do varão, foram confirmadas só pelos informantes Avá-Nhandeva e Paĩ-Tayterã ou Kaiowá.

No que se refere ao conceito 'cunhado', 'cunhada', se observa um resultado interessante: abandonou-se o parâmetro da distinção entre termos relacionais e não relacionais, como na maioria dos casos, mas se conservou o termo Guaraní t-ovaja, che r-ovaja como termo mais usado, só que o significado mudou de 'aquele que está em frente de mim', meu cunhado, com referência ao varão' a 'meu cunhado/ minha cunhada', sem distinção nem entre o sexo dos cunhados nem com respeito ao do falante. Em comparação com che rovaja, os hispanismos che kuñádo, che kuñáda se usam menos. O arcaísmo uke'i 'cunhada' (sem limitação à fala feminina) se conhece geralmente muito pouco. É termo lembrado na geração idosa da área bilíngue do Paraguai e do Brasil, mas praticamente não na Argentina (veja-se o mapa 4).

\section{Conclusão}

Em conclusão, o abandono das estruturas sociais indígenas e o peso constante da outra língua, o Espanhol, levaram e estão levando ainda ao abandono das estruturas semânticas do Guaraní tradicional, isto é das estruturas relacionais, e também à perda de muitos dos termos específicos do Guaraní. A terminologia atual do parentesco reflete a sociedade moderna, com menos estruturas hierárquicas familiares do que antes, com mais autonomia do indivíduo. As velhas estruturas hierárquicas conservaram-se apenas no núcleo familiar, na distinção relacional entre os filhos do varão e as crianças da mulher. 


\section{Referências}

Cerno, Leonardo. 2012. El Guaraní Correntino. Fonología, Gramática, Textos. Frankfurt - Bern, etc.

Dietrich, Wolf. 2010. Lexical evidence for a redefinition of Paraguayan 'Jopara'. STUF - Language Typology and Universals 63.1: Languages in contact with Spanish, ed. by Dik Bakker and Umberto Ansaldo, Berlin: Akademie Verlag: 39-51.

Domínguez, Ramiro (1966), El valle y la loma: comunicación en comunidades rurales, cap. IV: "Constantes estructurales en sociología rural", Asunción: EMASA, págs. 143-153. Reedições em 1995 y 2013.

Dooley, Robert A. 2006. Léxico Guarani: Dialeto Mbyá. Introdução, esboco gramatical, léxico. Cuiabá, MT: SIL.

Hoeller, Alfredo. 1932. Guarayo-Deutsches Wörterbuch. Guarayos - Hall/Tirol: Missionsprokura der P.P. Franziskaner.

Pereira, Levi Marques. 1999. Parentesco e organização social Kaiowá. Diss. de mestrado. Campinas: UNICAMP.

Montoya, Antonio Ruiz de. 1639. Tesoro de la lengua guaraní. Madrid: Iuan Sanchez. Reedição por Bartomeu Melià, Assunção: CEPAG, 2011.

Montoya, Antonio Ruiz de. 1640. Bocabulario de la lengua guaraní, Madrid: Iuan Sanchez. Reedição por Bartomeu Melià, Assunção: CEPAG, 2002.

Rodrigues, Aryon Dall'Igna e Cabral, Ana SuellyArruda Câmara. 2002, Revendo a classificação interna da família Tupí-Guaraní. Em: Cabral, Ana Suelly Arruda/ Rodrigues, Aryon Dall'Igna (organizadores), Línguas Indígenas Brasileiras: Fonologia, Gramática e História, Atas do I Encontro Internacional ..., Tomo I, Belém: EDUFPA, p. 327-337.

Service, Elman R. \& Helen S. (1954), Tobati: Paraguayan Town. Chicago: University of Chicago Press.

Thun, Harald. 2005. A dialetologia pluridimensional no Rio da Prata. Em: Stahl Zilles, Ana Maria (organizadora), Estudos de variação lingüística no Brasil e no Cone Sul, Porto Alegre: Editora da UFRGS, p. 63-92.

Thun, Harald - Aquino, Almidio - Dietrich, Wolf - Symeonidis, Haralambos (diretores). 2009. Atlas Lingüístico Guarani-Românico (ALGR), Tomo I: Léxico del cuerpo humano, elaborado por Wolf Dietrich y Haralambos Symeonidis, Kiel: Westensee-Verlag. Tomo II: Léxico del parentesco, elaborado por Wolf Dietrich, Guido Kallfell y Harald Thun (no prelo).

Data recebimento: $11 / 02 / 2014$.

Data aceite: $18 / 04 / 2014$. 


\section{Atlas Lingüístico Guaraní-Románico (ALGR) Mapa 110.1}

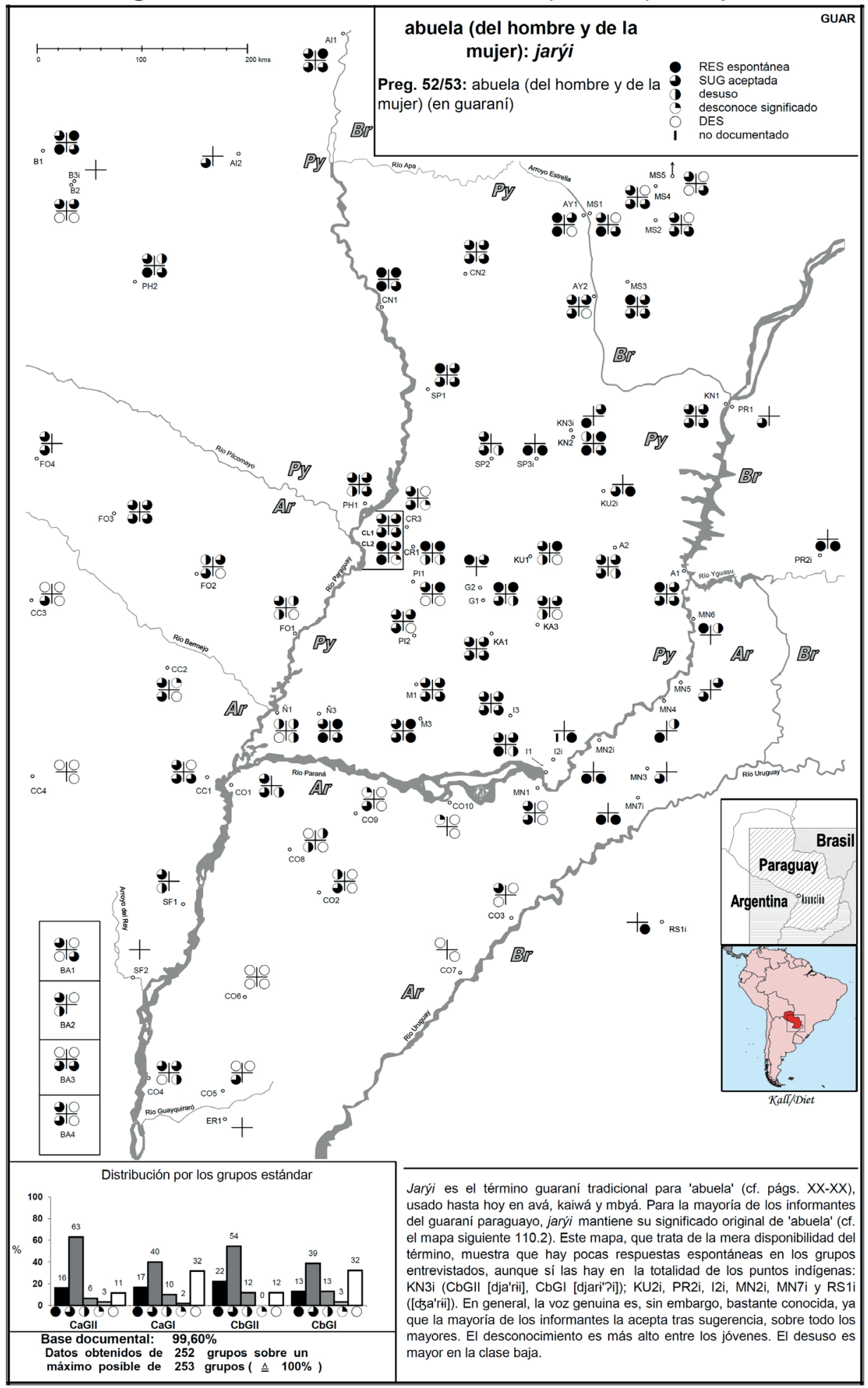

(1) $\mathcal{H}$. Thun, W. Dietrich, $\mathcal{H}$. Symeonidis 2005 


\section{Atlas Lingüístico Guaraní-Románico (ALGR) Mapa 104.2}

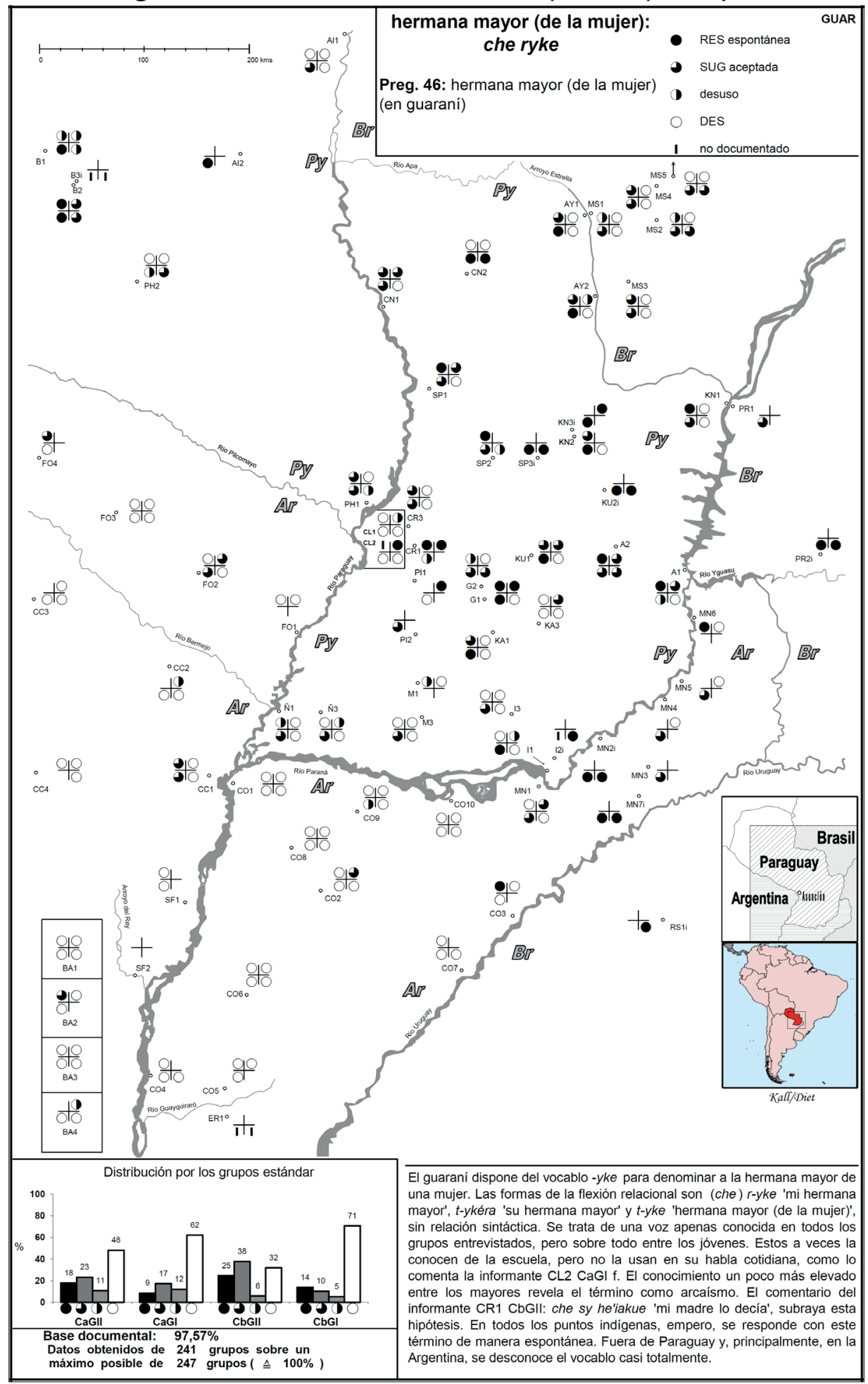

(C) $\mathcal{H}$. Thun, W. Dietrich, H. Symeonidis 2005 


\section{Atlas Lingüístico Guaraní-Románico (ALGR) Mapa 82.4}

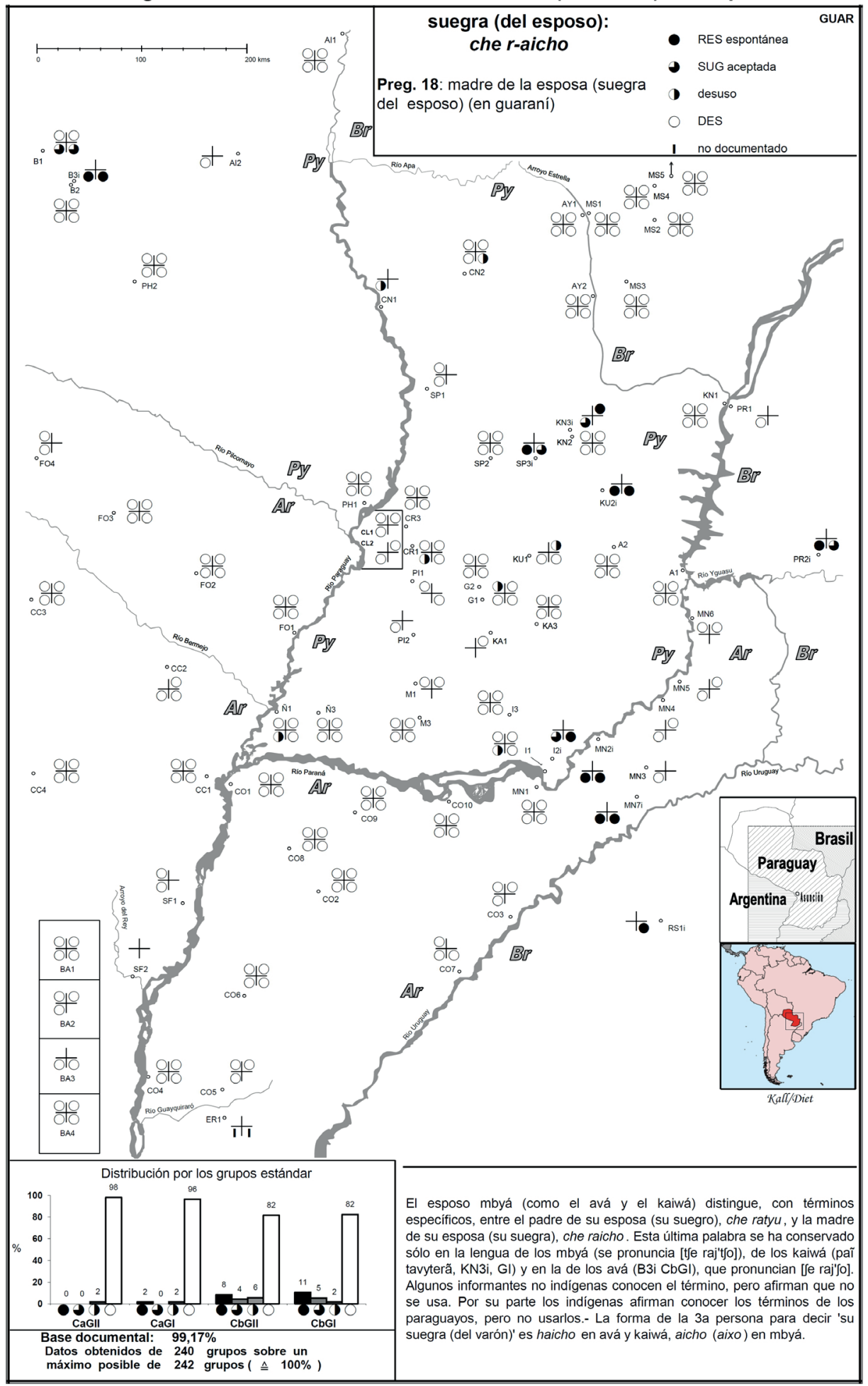

(C) H. Thun, W. Dietrich, $\mathcal{H}$. Symeonidis 2005 


\section{Atlas Lingüístico Guaraní-Románico (ALGR) Mapa 123.6}

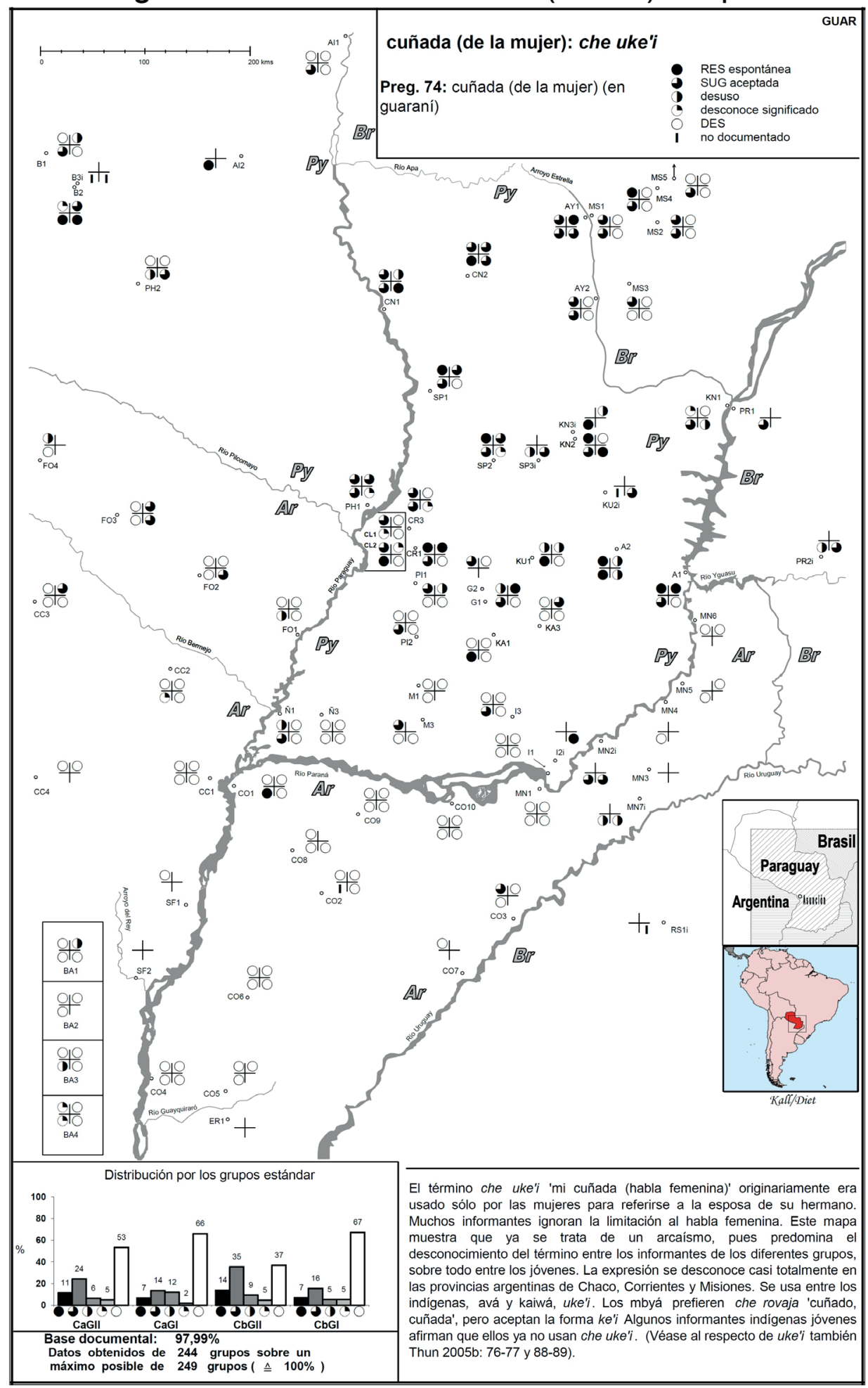

(Q) $\mathcal{H}$. Thun, W. Dietrich, $\mathcal{H}$. Symeonidis 2005 


\section{Atlas Lingüístico Guaraní-Románico (ALGR) Mapa 137.2}

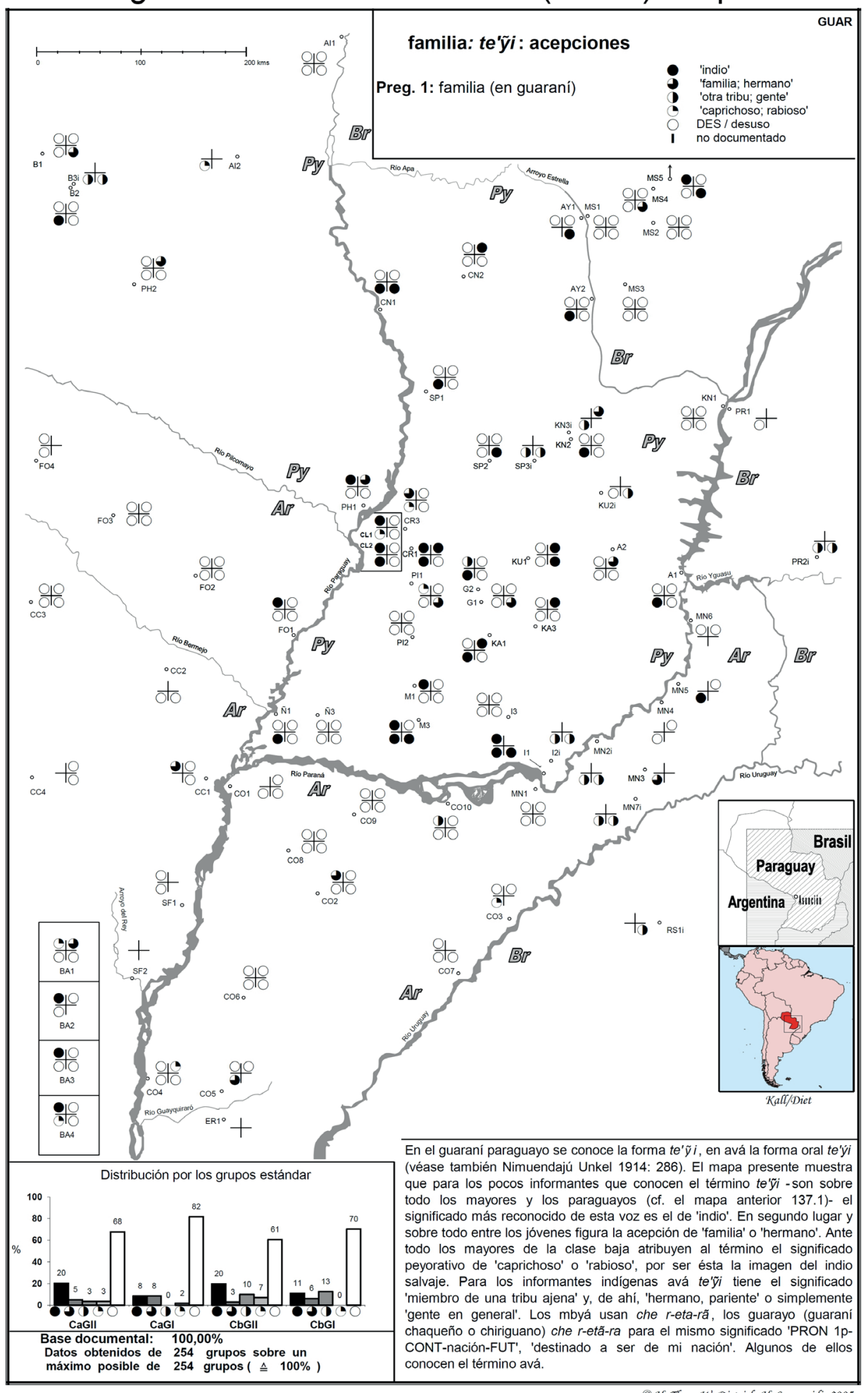

(C) $\mathcal{H}$. Thun, W. Dietrich, $\mathcal{H}$. Symeonidis 2005 